\title{
Comment on "Cavitons and spontaneous hot flow anomalies in a hybrid-Vlasov global magnetospheric simulation" by Blanco-Cano et al. (2018)
}

\author{
Gábor Facskó \\ Rhea System GmbH, TIZ Building, Robert Bosch Str. 7, 64293 Darmstadt, Germany \\ Correspondence: Gábor Facskó (g.facsko@ rheagroup.com)
}

Received: 16 January 2019 - Discussion started: 22 January 2019

Revised: 12 July 2019 - Accepted: 1 August 2019 - Published: 29 August 2019

Blanco-Cano et al. (2018) analysed the output of the Vlasiator global hybrid-Vlasov solver and intended to find spontaneous hot flow anomalies (SHFAs; Zhang et al., 2013; Omidi et al., 2013). This is a very nice paper about the development of the foreshock cavitons and magnetosheath cavities based on unique global hybrid-Vlasov simulations. However, the simulation results cannot reproduce the main features of the SHFAs. The SHFAs (and the HFAs) show density and magnetic field magnitude drops in their cavity. The magnetic field is turbulent in the cavity. The temperature is very high in them, a few million kelvin. The solar wind direction turns away from the radial direction and slows down (Facskó et al., 2010; Zhang et al., 2013; Omidi et al., 2013). The latter features gave the name of the phenomenon, hence I had serious concerns about whether the authors had detected SHFA in the paper above.

In Figs. 3, 7, and 9 of the paper above, the authors see density and magnetic field drops. The simulated phenomena are not significantly hotter than the surrounding foreshock plasma. The foreshock plasma temperature is never observed at $10^{7} \mathrm{~K}$. Hence, locating in the foreshock cannot be an excuse for the missing feature of the phenomena. The authors also see "[...] deviations from the bulk solar wind velocity are observed throughout the foreshock, and they are not prominent enough inside SHFAs to be unambiguously identified.". The phenomenon that does not show anomalous flow cannot be called spontaneous hot flow anomaly.

The SHFAs are surrounded by density and magnetic field increases at the edge of the phenomena. Their presence proves that the cavity is not in equilibrium and expands. The hybrid simulations of Omidi et al. (2013) could present these shoulders (Lin, 2002, could also have simulated them for
HFAs). Furthermore, these increases lead to the observed depletion of the solar wind velocity because the deceleration of the solar wind comes from the bad fitting and plasma moment calculation (Parks et al., 2013; Kecskeméty et al., 2006, Figs. 3, 7). Hence, it is possible to explain the missing solar wind deceleration if these increases are present. If both features are missing, the phenomena cannot be SHFA.

The authors also study foreshock cavitons, magnetosheath filaments, and structures in the paper above. My comments are limited only to the identification and analysis of the "SHFA events" of the simulation. Based on the remarks described above, I am sure that the features in the Vlasiator simulations are not SHFAs. However, these questionable events could develop to an SHFA. Zhang et al. (2013) observed SHFA-like events without significant solar wind deceleration. As Zhang et al. (2010) discovered and introduced the phenomenon of so-called proto-HFA, Zhang et al. (2013) discovered the phenomena of proto-SHFA. These proto-SHFAs were simulated by the Vlasiator code and misinterpreted by the authors.

Data availability. No data sets were used in this article.

Competing interests. The author declares that there is no conflict of interest.

Acknowledgements. Gábor Facskó thanks Sophie Burley for improving the English of the paper. 
Review statement. This paper was edited by Christopher Owen and reviewed by Andrey Samsonov.

\section{References}

Blanco-Cano, X., Battarbee, M., Turc, L., Dimmock, A. P., Kilpua, E. K. J., Hoilijoki, S., Ganse, U., Sibeck, D. G., Cassak, P. A., Fear, R. C., Jarvinen, R., Juusola, L., Pfau-Kempf, Y., Vainio, R., and Palmroth, M.: Cavitons and spontaneous hot flow anomalies in a hybrid-Vlasov global magnetospheric simulation, Ann. Geophys., 36, 1081-1097, https://doi.org/10.5194/angeo-36-10812018, 2018.

Facskó, G., Trotignon, J. G., Dandouras, I., Lucek, E. A., and Daly, P. W.: Study of hot flow anomalies using Cluster multi-spacecraft measurements, Adv. Space Res., 45, 541-552, https://doi.org/10.1016/j.asr.2009.08.011, 2010.

Kecskeméty, K., Erdős, G., Facskó, G., Tátrallyay, M., Dandouras, I., Daly, P., and Kudela, K.: Distributions of suprathermal ions near hot flow anomalies observed by RAPID aboard Cluster, Adv. Space Res., 38, 1587-1594, https://doi.org/10.1016/j.asr.2005.09.027, 2006.

Lin, Y.: Global hybrid simulation of hot flow anomalies near the bow shock and in the magnetosheath, Planet. Space Sci., 50, 577-591, https://doi.org/10.1016/S0032-0633(02)00037-5, 2002.
Omidi, N., Zhang, H., Sibeck, D., and Turner, D.: Spontaneous hot flow anomalies at quasi-parallel shocks: 2. Hybrid simulations, J. Geophys. Res.-Space, 118, 173-180, https://doi.org/10.1029/2012JA018099, 2013.

Parks, G. K., Lee, E., Lin, N., Fu, S. Y., McCarthy, M., Cao, J. B., Hong, J., Liu, Y., Shi, J. K., Goldstein, M. L., Canu, P., Dandouras, I., and Rème, H.: Reinterpretation of Slowdown of Solar Wind Mean Velocity in Nonlinear Structures Observed Upstream of Earth's Bow Shock, Astrophys. J. Lett., 771, L39, https://doi.org/10.1088/2041-8205/771/2/L39, 2013.

Zhang, H., Sibeck, D. G., Zong, Q.-G., Gary, S. P., McFadden, J. P., Larson, D., Glassmeier, K.-H., and Angelopoulos, V.: Time History of Events and Macroscale Interactions during Substorms observations of a series of hot flow anomaly events, J. Geophys. Res.-Space, 115, A12235, https://doi.org/10.1029/2009JA015180, 2010.

Zhang, H., Sibeck, D. G., Zong, Q.-G., Omidi, N., Turner, D., and Clausen, L. B. N.: Spontaneous hot flow anomalies at quasiparallel shocks: 1. Observations, J. Geophys. Res.-Space, 118, 3357-3363, https://doi.org/10.1002/jgra.50376, 2013. 